\title{
Perioperative Use of Methotrexate and Tumor Necrosis Factor $\alpha$ Inhibitors Combination Therapy Is Not Likely to Increase Post-Operative Infection Rate in the National Veterans Health Administration Administrative Databases
}

\author{
Hsin-Hsuan Juo', Anders Peck², Sarah E. Monsell ${ }^{3}$, Bernard Ng1 ${ }^{*}$ \\ ${ }^{1}$ Department of Medicine, Division of Rheumatology, University of Washington, VA Puget Sound Healthcare System, \\ Seattle, USA \\ ${ }^{2}$ The Seattle Arthritis Clinic, University of Washington Medicine, Northwest Hospital, Seattle, USA \\ ${ }^{3}$ Department of Biostatistics, University of Washington, Seattle, USA \\ Email: *Bernard.Ng@va.gov
}

How to cite this paper: Juo, H.-H., Peck, A., Monsell, S.E. and Ng, B. (2019) Perioperative Use of Methotrexate and Tumor Necrosis Factor $\alpha$ Inhibitors Combination Therapy Is Not Likely to Increase Post-Operative Infection Rate in the National Veterans Health Administration Administrative Databases. Open Journal of Rheumatology and Autoimmune Diseases, 9, 1-13.

https://doi.org/10.4236/ojra.2019.91001

Received: December 3, 2018

Accepted: January 31, 2019

Published: February 3, 2019

Copyright $\odot 2019$ by author(s) and Scientific Research Publishing Inc. This work is licensed under the Creative Commons Attribution International License (CC BY 4.0).

http://creativecommons.org/licenses/by/4.0/

\section{c) (i) Open Access}

\begin{abstract}
Objective: The aim of the study is to assess the risk of post-operative outcome in rheumatoid arthritis (RA) patients continuing versus stopping combination therapy of methotrexate (MTX) and hydroxychloroquine (HCQ) or tumor necrosis factor $\alpha$ inhibitors (TNF) prior to surgery. Methods: Using the United States Veterans Affairs (VA) databases, we identified surgical procedures in a 17-year cohort of RA patients. Among those patients, those on MTX + HCQ or MTX + TNF were identified. Post-operative outcome variables include infection, length of post-operative hospital stay and death. Results: We identified a total of 29,708 surgeries in RA patients. Among them, we identified the most recent elective surgeries without pre-operative infection in 16,174 patients. There were 783 and 550 patients on MTX + HCQ and MTX + TNF, respectively. The rates of post-op infection were $5 \%$ and $4 \%$ for the MTX + HCQ and MTX + TNF continuing medication groups, respectively, similar to the general RA population (5\%). Sensitivity analyses at various time points of discontinuation combination therapies prior to surgery did not show significant change in terms of infection. Conclusions: The prevalence of adverse outcome is low. The proportion of post-operative infection in continuing and discontinuing medicine groups is similar for both MTX + HCQ and MTX + TNF. While we were unable to formally compare propor-
\end{abstract}


tions of post-operative infection among the two groups, these preliminary findings do not support the hypothesis that continuing either MTX + TNF or MTX + HCQ combination during perioperative period increases post-operative infection compared with discontinuation prior to therapy.

\section{Keywords}

Rheumatoid Arthritis, Perioperative Management, Outcome, Methotrexate and Tumor Necrosis Factor Combination Therapy

\section{Introduction}

Rheumatoid arthritis (RA) is a chronic inflammatory arthritis characterized by joint pain and swelling, as well as other extra-articular manifestations. If not treated optimally, RA can cause progressive joint damage that eventually leads to significant morbidity and mortality. Given the natural history of RA and lack of effective treatments in the past, surgical procedures, especially orthopedic procedures, have been very common among RA patients [1]. RA patients have worse surgical outcomes, including the severity of pain, function scores, and increased rates of prosthetic joint infection, when compared with patients with osteoarthritis undergoing similar procedures [2] [3].

Treatment for RA has advanced significantly over the past decade with regimens composed of synthetic disease modifying anti-rheumatic drugs (DMARDs) and targeted biologic agents (BA), such as tumor necrosis factor $\alpha$ inhibitors (TNF), as well as therapies combining the two (combination therapies). As these are immunosuppressive or immunomodulating agents, there is concern of perioperative use of antirheumatic drugs leading to increased risk of infectious complications and delayed wound healing that result in adverse outcomes during the post-operative period. Stopping therapy, on the other hand, could lead to an RA flare, which may limit the patients' ability to participate in post-operative physical therapy, increase perioperative steroid use, and may delay recovery from surgery [4] [5] [6].

There is an unmet need for literature on perioperative management of antirheumatic medications. The DMARD that has been best studied in the perioperative setting is MTX use in the context of orthopedic surgeries [7] [8]. Continuation of MTX in the perioperative setting is currently recommended by several groups [9] [10] [11]. The best studied class of biologic agents is the TNF $\alpha$ inhibitors, but the current literature is conflicting with some studies demonstrating no increased risk of perioperative infection [12] [13] and other studies showing the opposite [14] [15] [16]. Most recently, American College of Rheumatology (ACR) and American Association of Hip and Knee Surgeons have published guidelines regarding perioperative management of antirheumatic medication in patients with rheumatic diseases [17]. The guidelines recommend continuing DMARDs and stopping most of the BA one dosing interval plus seven days prior 
to the surgery. The British Society for Rheumatology also recommends stopping TNF $\alpha$ inhibitors 3 - 5 drug half-lives prior to surgery [18]. However, most of the recommendations on BAs are made based on expert opinions and extrapolation of clinical trial data on non-surgical patients. There could be a difference in patient demographics between RA patients who were enrolled in clinical trial and those who underwent surgery. Furthermore, although combination therapies are commonly used, there is a lack of literature regarding combination therapy in surgical patients, which make clinical decisions difficult for practicing rheumatologists and surgeons.

Thus, in this study, we aim to assess whether post-operative outcomes, specifically post-operative infectious complications, in RA patients undergoing surgical procedures is greater in patients continuing MTX + HCQ or MTX + TNF combination therapies compared with patients who stop their medications prior to surgery.

\section{Materials and Methods}

The study was approved by the Institutional Review Board at the Puget Sound Veterans Administration Medical Center (MIRB\#781) and University of Washington (HSD\#50933).

\subsection{Data Source}

All analyses were performed using the National Veterans Health Administration Administrative databases, including the Veterans Affairs (VA) inpatient data, VA outpatient data, pharmacy benefits management data, decision support system laboratory files, and the Veterans Administration Surgical Quality Improvement Program (VASQIP) [19]. These databases provided a comprehensive documentation of surgeries and outcomes, including post-operative infections, length of post-operative hospital stay and death, among all Veterans across the nation. A Veteran is defined as a person who had served in the active military service in the USA, who was discharged honorably from service and would be eligible to access VA healthcare.

\subsection{Cohort Selection}

We identified a cohort of surgeries performed on RA patients at VA sites across the nation between October 1, 1999 and November 16, 2016. All types of surgery were included in this analysis. RA patients were identified using a previously validated algorithm: [a] two or more RA diagnosis codes (International Classification of Diseases 9 code of 714) at least 6 months apart; [b] at least one rheumatology clinic visit; [c] RA diagnosis code entered at the last rheumatology clinic visit; and [d] at least one DMARD or BA was dispensed for a total duration of 6 months or more [20] [21].

We eliminated emergency surgeries to avoid potential poor outcome due to lack to preoperative preparation. When a patient had multiple surgeries, we se- 
lected the most recent surgery without prior infection in order to better reflect current treatment for RA, given that there has been a significant change in therapeutic options in the past decade.

Next, RA patients who were on MTX + HCQ and MTX + TNF combination therapies prior to surgery were identified. The pharmacy database was used to obtain information on patients' refill periods. We used a previously validated method to determine whether the medication had been stopped prior to or continued through the perioperative period based on the refill periods [22]. Continuing therapy must fulfill two criteria: [a] the patient must be a "user" of the medication and $[\mathrm{b}]$ the medication must be "effective" during perioperative period. An MTX or HCQ user is defined as an RA patient who taken the medication for more than one month within the period 6 months prior to the surgery. MTX and HCQ are considered "effective" if they were continued throughout the surgery or discontinued within 3 months prior to surgery. A TNF user is defined as an RA patient who is on the TNF inhibitor for more than a month within the period two months prior to the surgery. TNF inhibitors are considered "effective" if they were continued throughout the surgery or discontinued within 2 dosing intervals prior to surgery. For example, etanercept is considered effective if it was discontinued within 2 weeks prior to the surgery and adalimumab within 4 weeks. TNF inhibitors included in the study consist of the most commonly used TNF inhibitors at the VA, including etanercept, and adalimumab. Other TNF inhibitors (e.g. infliximab, certolizumab and golimumab) were not included in the study due to small sample sizes.

Applying the above-mentioned definitions, all patients identified were further divided into three subgroups: [a] continuing both medications, [b] discontinuing both medications, [c] other use pattern. Patients who are off medication, on monotherapy or other medication combinations were excluded from the analysis. In other words, all surgeries that happened before the initiation of the specific RA therapies were excluded from the study.

\subsection{Statistical Analysis}

All statistical analyses were performed using STATA V.12.0, College Station, Texas, USA.

Chi square (a) or Fisher's Exact test (b) was used to compare categorical variables between continuing and discontinuing both medications subgroups. Kruskal-Wallis test (c) was used to compare continuous variables between continuing and discontinuing both medications subgroups. The demographic variables of interest included sex, age, chronic steroid use, smoking, diabetes mellitus, pre-albumin, and the modified Charlson surgery comorbidity score. The Charlson surgical comorbidity score was modified by excluding ICD9 codes related to RA, such as 714.xx and 725, to avoid bias [23] [24] [25]. Post-operative outcome included infectious complications within 30 days such as pneumonia, sepsis, UTI and wound infection, as well as post-operative length of hospital stays and death within 90 days. We planned to use multivariable logistic regres- 
sion with propensity scores to compare the proportion of surgical patients with infectious complications between those continuing vs. discontinuing medications. The alpha for statistical significance was set at 0.05 for all analyses. For sensitivity analyses, we used Fisher's exact test to examine the differences in surgical patients with infectious complications between those who continued medication vs. discontinued medications discontinued at various time points before surgery.

\section{Results}

\subsection{Patient Characteristics}

We identified a total of 29,708 surgeries among 17,293 RA patients between October 1, 1999 and November 16, 2016 from VASQIP database. One thousand five hundred and thirty-nine emergency surgeries, 1947 surgeries with pre-operative infection, and 10,048 previous surgeries were removed.

Application of the aforementioned criteria resulted in 16,174 RA patients eligible for analysis. The mean age at surgery of those patients was 64 (SD 10.67). Eighty eight percent were male and $64 \%$ were non-Hispanic Caucasian. The mean of BMI was 29 (SD 6.25). The majority of patients were in the category of non-DM or diet-controlled DM (82\%) and were not on chronic steroid (79\%). The mean prealbumin level was 3.83 (SD 0.54). The median modified Charlson score was 2 . The post-operative infection rate was $5.05 \%$, including $1.09 \%$ of urinary tract infection, $2.35 \%$ of wound infection, $1.04 \%$ of sepsis, and $1.19 \%$ of pneumonia. The death rate within 90 days after the surgery was $0.01 \%$. There were 9786 patients who were off the combination therapy during the perioperative period as the surgery was done before they were diagnosed with RA. There were $783(5 \%)$ and 550 (3\%) patients on MTX + HCQ and MTX + TNF combination therapy, respectively. Each group was further divided into three subgroups: (a) continued both medications prior to surgery, (b) discontinued both and (c) other use pattern. Figure 1 illustrates consort diagram for the patients/surgeries selection.

In the MTX + HCQ group, there were 14 (2\%) patients who discontinued both medication, 656 (84\%) patients who continued both medications, and 113 (14\%) patients with other use patterns. In the MTX + TNF group, there were 6 (1\%) patients who discontinued both medication, 363 (66\%) patients who continued both, and 181 (33\%) patients with other use patterns. Comparing the continued vs. discontinued medication subgroups within each treatment groups, there was no statistical difference in patient demographics, including sex, chronic steroid use, smoking diabetes mellitus, pre-albumin, and the modified Charlson surgery comorbidity score. Although the p-value is less than 0.01 in the MTX + TNF group, there were very few patients in the discontinuing medication group. Table 1 illustrates patient demographics for both combination therapies.

\subsection{Surgery Characteristics}

The most common surgery in our cohort was orthopedic surgeries (20\%), 


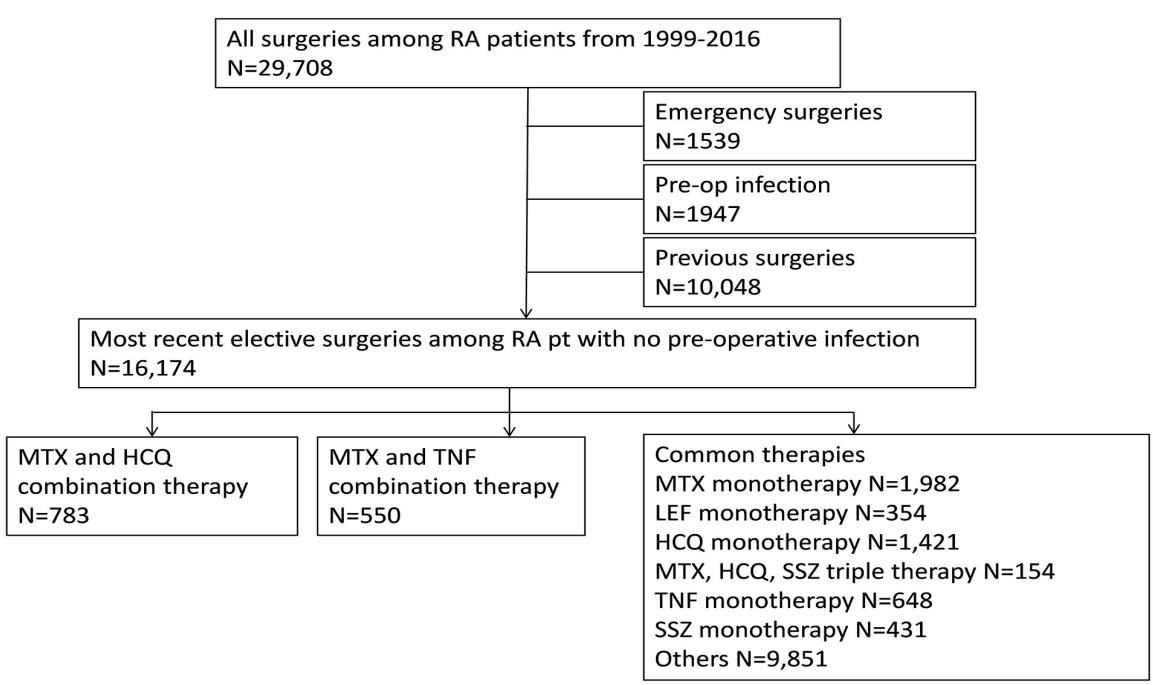

Figure 1. Patient selection (attached in a different file).

including both arthroplasty and joint replacement surgery. Other surgeries include hernia surgeries (11\%), cholecystectomies (5\%), and urological procedures (5\%), such as cystoscopy and trans-ureteral resection of prostate.

Post-operative outcome: infection within 30 days, length of post-operative hospital stays and death within 90 days.

The median length of post-operative hospital stay was approximately 5 days, excluding same day surgery, in both combination therapy groups.

Among 14 patients who discontinued MTX + HCQ, there was one (7.1\%) post-operative infection and one $(7.1 \%)$ death. Among the 636 patients who continued therapy, there were 29 (4.3\%) post-operative infections and 18 (3\%) deaths.

Among 6 patients who discontinued MTX + TNF, there were neither postoperative infections nor deaths. Among the 425 patients who continued medication, there were $22(5 \%)$ post-operative infections and $1(<0.1 \%)$ deaths in the group that continued medication.

Due to low prevalence of both infection and death, we were unable to analyze our data using multivariable logistic regression. Still, the infection rate is similar for general RA patients (5\%) and patients who are on the two combinations (4\% and 5\%). Table 2 illustrates the surgery characteristics and outcome.

Sensitivity analyses of individual combinations revealed no statistically significant difference in the prevalence of post-operative infection when discontinuing MTX + HCQ therapy 1 month, 2 months and 3 months prior to the surgery. Comparable results were observed with etanercept and adalimumab when discontinued at various dosing intervals. Table 3 describes the sensitivity analysis on post-operative infection within 30 days.

\section{Discussion}

Recently published ACR guidelines on perioperative management of antirheumatic medications provides guidance based on indirect interpretation of data 
Table 1. Demographics.

\begin{tabular}{|c|c|c|c|c|c|c|c|c|c|c|c|c|c|c|}
\hline \multirow[b]{3}{*}{ N (\%) } & \multicolumn{7}{|c|}{$\mathrm{MTX}+\mathrm{HCQ}$} & \multicolumn{7}{|c|}{$\mathrm{MTX}+\mathrm{ADA}$} \\
\hline & \multicolumn{2}{|c|}{$\begin{array}{c}\text { Discontinued } \\
\text { medication }\end{array}$} & \multicolumn{2}{|c|}{$\begin{array}{c}\text { Continued } \\
\text { medication }\end{array}$} & \multicolumn{2}{|c|}{$\begin{array}{c}\text { Used other } \\
\text { patterns }\end{array}$} & \multirow[t]{2}{*}{$\mathrm{p}$} & \multicolumn{2}{|c|}{$\begin{array}{l}\text { Discontinued } \\
\text { medication }\end{array}$} & \multicolumn{2}{|c|}{$\begin{array}{l}\text { Continued } \\
\text { medication }\end{array}$} & \multicolumn{2}{|c|}{$\begin{array}{l}\text { Used other } \\
\text { patterns }\end{array}$} & \multirow[t]{2}{*}{$\mathrm{p}$} \\
\hline & 14 & $(100)$ & 656 & $(100)$ & 113 & $(100)$ & & 6 & $(100)$ & 363 & $(100)$ & 181 & $(100)$ & \\
\hline Age at operation (\%) & & & & & & & $0.32^{\mathrm{c}}$ & & & & & & & $0.04^{\mathrm{c}}$ \\
\hline$<50$ & 1 & (6) & 26 & $(4)$ & 9 & (8) & & 0 & $(0)$ & 17 & $(5)$ & 8 & (4) & \\
\hline $50-59$ & 3 & (19) & 130 & (19) & 21 & (18) & & 4 & (67) & 74 & (20) & 45 & (25) & \\
\hline $60-69$ & 6 & (38) & 295 & (44) & 49 & (41) & & 1 & (17) & 164 & (45) & 88 & (49) & \\
\hline $70-79$ & 2 & (13) & 156 & (23) & 22 & (18) & & 1 & (17) & 84 & (23) & 37 & (20) & \\
\hline $80-89$ & 0 & $(0)$ & 36 & (5) & 6 & (5) & & 0 & $(0)$ & 21 & (6) & 2 & (1) & \\
\hline $90+$ & 2 & (13) & 13 & (2) & 6 & $(5)$ & & 0 & $(0)$ & 3 & (1) & 1 & (1) & \\
\hline Missing & 2 & (13) & 12 & (2) & 6 & (5) & & 0 & (0) & 0 & (0) & 0 & (0) & \\
\hline Mean (SD) & 62.82 & $(9.04)$ & 65.74 & $(8.86)$ & 64.27 & $(10.98)$ & & 58.66 & $(7.61)$ & 65.67 & $(9.62)$ & 63.11 & $(9.16)$ & \\
\hline $\operatorname{Sex}(\%)$ & & & & & & & $0.28^{\mathrm{b}}$ & & & & & & & $0.2^{\mathrm{b}}$ \\
\hline Female & 3 & (21) & 74 & (11) & 16 & (14) & & 1 & (17) & 34 & (9) & 25 & $(14)$ & \\
\hline Male & 11 & (79) & 582 & (89) & 97 & (86) & & 5 & (83) & 329 & (91) & 156 & $(86)$ & \\
\hline Race (\%) & & & & & & & $0.88^{\mathrm{a}}$ & & & & & & & $0.03^{\mathrm{a}}$ \\
\hline White, not Hispanic & 9 & (64) & 452 & (69) & 76 & (67) & & 2 & (33) & 279 & (77) & 130 & $(72)$ & \\
\hline White, Hispanic & 0 & (0) & 24 & $(4)$ & 4 & (4) & & 0 & (0) & 6 & (2) & 5 & (3) & \\
\hline African American & 2 & (14) & 69 & (11) & 11 & (10) & & 2 & (33) & 25 & (7) & 15 & (8) & \\
\hline $\begin{array}{l}\text { Asian, Pacific } \\
\text { Islander }\end{array}$ & 0 & (0) & 4 & (1) & 0 & (0) & & 0 & (0) & 0 & $(0)$ & 1 & (1) & \\
\hline Others & 2 & (14) & 48 & (7) & 13 & (12) & & 2 & (33) & 27 & (7) & 11 & (6) & \\
\hline Missing & 1 & (7) & 59 & (9) & 9 & (8) & & 0 & (0) & 26 & (7) & 19 & (10) & \\
\hline BMI (\%) & & & & & & & $0.44^{\mathrm{c}}$ & & & & & & & $0.72^{c}$ \\
\hline$<18.5$ & 1 & (7) & 5 & (1) & 1 & (1) & & 0 & (0) & 0 & (0) & 3 & (2) & \\
\hline $18.5-<25$ & 4 & (29) & 118 & (18) & 21 & (19) & & 1 & (17) & 71 & (20) & 28 & (15) & \\
\hline $25-<30$ & 3 & (21) & 155 & (24) & 35 & (31) & & 0 & (0) & 105 & (29) & 55 & $(30)$ & \\
\hline$\geq 30$ & 5 & (36) & 184 & (28) & 33 & (29) & & 1 & (17) & 124 & (34) & 65 & $(36)$ & \\
\hline Missing & 1 & (7) & 194 & (30) & 23 & (20) & & 4 & (67) & 63 & (17) & 30 & (17) & \\
\hline Mean (SD) & 27.68 & $(5.78)$ & 29.06 & $(5.90)$ & 29.01 & $(5.50)$ & & 27.39 & $(7.74)$ & 29.46 & $(6.28)$ & 29.27 & $(5.77)$ & \\
\hline Diabetes (DM) (\%) & & & & & & & $0.94^{\mathrm{b}}$ & & & & & & & $0.28^{\mathrm{b}}$ \\
\hline $\begin{array}{l}\text { No DM or diet } \\
\text { only }\end{array}$ & 12 & (86) & 540 & (82) & 95 & (84) & & 3 & $(50)$ & 277 & (76) & 140 & (77) & \\
\hline Oral DM drugs & 2 & (14) & 75 & (11) & 10 & (9) & & 0 & (0) & 54 & (15) & 27 & (15) & \\
\hline Insulin use & 0 & (0) & 41 & (6) & 8 & (7) & & 3 & $(50)$ & 32 & (9) & 14 & (8) & \\
\hline $\begin{array}{c}\text { Modified } \\
\text { Charlson Score (\%) }\end{array}$ & & & & & & & $0.80^{c}$ & & & & & & & $0.49^{c}$ \\
\hline 0 & 5 & (15) & 150 & (11) & 25 & (11) & & 2 & (11) & 91 & (12) & 46 & (13) & \\
\hline 1 to 2 & 3 & (9) & 179 & (14) & 33 & (14) & & 1 & (5) & 92 & (13) & 54 & (15) & \\
\hline 3 to 4 & 1 & (3) & 103 & $(8)$ & 13 & (6) & & 0 & (0) & 55 & (8) & 28 & (8) & \\
\hline 5 to 6 & 2 & (6) & 54 & (4) & 7 & (3) & & 2 & (11) & 34 & (5) & 11 & (3) & \\
\hline 7 to 8 & 2 & (6) & 36 & (3) & 5 & (2) & & 1 & (5) & 11 & (2) & 4 & (1) & \\
\hline
\end{tabular}


Continued

\begin{tabular}{|c|c|c|c|c|c|c|c|c|c|c|c|c|c|c|}
\hline $9+$ & 0 & $(0)$ & 33 & (3) & 7 & (3) & & 0 & (0) & 13 & (2) & 2 & (1) & \\
\hline Missing & 1 & (3) & 101 & (8) & 20 & (9) & & 0 & (0) & 67 & (9) & 36 & $(10)$ & \\
\hline Median & 2 & & 2 & & 2 & & & 3 & & 2 & & 2 & & \\
\hline $\begin{array}{c}\text { Chronic steroid use } \\
(\%)\end{array}$ & & & & & & & $0.67^{\mathrm{b}}$ & & & & & & & $0.33^{\mathrm{b}}$ \\
\hline No & 11 & (79) & 434 & (66) & 76 & (67) & & 3 & $(50)$ & 271 & $(75)$ & 132 & $(73)$ & \\
\hline Yes & 3 & (21) & 222 & (34) & 37 & (33) & & 3 & $(50)$ & 92 & $(25)$ & 49 & $(27)$ & \\
\hline Pre-albumin level & & & & & & & $0.59^{c}$ & & & & & & & $0.03^{\mathrm{c}}$ \\
\hline Mean (SD) & 3.72 & $(0.83)$ & 3.84 & $(0.47)$ & 3.91 & $(0.46)$ & & 3.2 & $(0.53)$ & 3.87 & $(0.46)$ & 3.9 & $(0.48)$ & \\
\hline
\end{tabular}

Notes: Chi square (a) or Fishe's exact test (b) for categorical variables, Kruskal-Wallis test (c) for continuous variables. Race evaluated for non-Hispanic White vs. all others. Diabetes evaluated as oral DM drugs and insulin use vs. no DM or diet only. Percent (\%); Standard deviation (SD).

Table 2. Surgery characteristics and outcomes.

\begin{tabular}{|c|c|c|c|c|c|c|c|c|c|c|}
\hline \multirow[b]{3}{*}{ N (\%) } & \multicolumn{5}{|c|}{ MTX + HCQ } & \multicolumn{5}{|c|}{ MTX + ADA } \\
\hline & \multicolumn{2}{|c|}{$\begin{array}{l}\text { Discontinued } \\
\text { medication }\end{array}$} & \multicolumn{2}{|c|}{$\begin{array}{l}\text { Continued } \\
\text { medication }\end{array}$} & \multirow[t]{2}{*}{$\mathrm{p}$} & \multicolumn{2}{|c|}{$\begin{array}{l}\text { Discontinued } \\
\text { medication }\end{array}$} & \multicolumn{2}{|c|}{$\begin{array}{l}\text { Continued } \\
\text { medication }\end{array}$} & \multirow[t]{2}{*}{$\mathrm{p}$} \\
\hline & 14 & $(100)$ & 656 & $(100)$ & & 6 & $(100)$ & 363 & $(100)$ & \\
\hline Surgery type (\%) & & & & & $0.75^{\mathrm{b}}$ & & & & & $0.30^{\mathrm{b}}$ \\
\hline Orthopedic & 12 & (86) & 520 & (79) & & 5 & (83) & 286 & (79) & \\
\hline Others & 2 & (14) & 136 & (21) & & 1 & (17) & 77 & (21) & \\
\hline Days post-op hospitalization & & & & & $0.7^{c}$ & & & & & $0.5^{\mathrm{c}}$ \\
\hline Mean (SD) & 4.9 & $(4.25)$ & 4.97 & $(6.24)$ & & 5 & $(2.12)$ & 5.11 & $(5.11)$ & \\
\hline Death within 90 days of surgery & & & & & $0.33^{\mathrm{b}}$ & & & & & $1^{\mathrm{b}}$ \\
\hline No & 13 & (93) & 638 & (97) & & 6 & $(100)$ & 362 & $(100)$ & \\
\hline Yes & 1 & (7) & 18 & (3) & & 0 & (0) & 1 & (0) & \\
\hline
\end{tabular}

Notes: p-values are for those who discontinue both medications vs. those who continue both medications. Fisher's exact test (b), Kruskal-Wallis test (c). ${ }^{*}$ MTX + HCQ was discontinued 3 months prior to surgery. MTX + TNF was discontinued one dosing interval prior to the surgery.

extrapolated from non-surgical patients enrolled in clinical trials. Direct evidence and literature are still lacking. Our study has the advantage of a large VA population of RA patients with long follow-up period [26]. In addition, the VASQIP database is a validated, outcome-based, risk-adjusted and peer-controlled database, which provided extremely reliable and standardized outcomes, allowing for confidence in our endpoints without necessitating chart review [27]. Moreover, using the VA pharmacy database allows us to track the dose and duration of DMARDs and BAs without recall bias. With these two comprehensive databases, we are able to provide some, although limited, evidence that suggests discontinuing MTX, HCQ, ETA and ADA has no significant change in post-operative outcome.

As mentioned in the introduction, TNF $\alpha$ inhibitor monotherapy has been assessed in several studies both in RA and in inflammatory bowel disease, with some results demonstrating increased risk of infection [14] [15] [16] [28] and other results showing no increased risk [12] [13] [29]. There is no literature looking at combination therapy to date. Our data suggests that these two 
Table 3. Sensitivity analyses on post-operative infection within 30 days.

(a)

\begin{tabular}{cccccc}
\hline & \multicolumn{5}{c}{ MTX + HCQ } \\
\hline $\begin{array}{c}\text { Time when both medications were } \\
\text { discontinued }\end{array}$ & $\begin{array}{c}\text { Discontinued } \\
\text { medication }\end{array}$ & $\begin{array}{c}\text { Continued } \\
\text { medication }\end{array}$ & p \\
\hline 1) month prior N (\%) & 59 & $(100)$ & 526 & $(100)$ & $1^{\mathrm{b}}$ \\
Infections No & 57 & $(97)$ & 503 & $(96)$ & \\
Yes & 2 & $(3)$ & 23 & $(4)$ & \\
2) months prior N (\%) & 30 & $(100)$ & 615 & $(100)$ & $0.65^{\mathrm{b}}$ \\
Infections No & 28 & $(93)$ & 586 & $(95)$ & \\
Yes & 2 & $(7)$ & 29 & $(5)$ & \\
3) months prior N (\%) & 14 & $(100)$ & 656 & $(100)$ & $0.47^{\mathrm{b}}$ \\
Infections No & 13 & $(93)$ & 627 & $(96)$ & \\
Yes & 1 & $(7)$ & 29 & $(4)$ & \\
\hline
\end{tabular}

(b)

\begin{tabular}{cccccc}
\hline & \multicolumn{5}{c}{ MTX + ETA } \\
\hline $\begin{array}{c}\text { Time when both medications were } \\
\text { discontinued }\end{array}$ & \multicolumn{2}{c}{ Discontinued } & \multicolumn{2}{c}{ Continued } \\
medication & 6 & $(100)$ & 228 & $(100)$ & $1^{\text {b }}$ \\
\hline 7 days prior N (\%) & 6 & $(100)$ & 217 & $(95)$ & \\
Infections No & 0 & $(0)$ & 11 & $(5)$ & \\
Yes & 5 & $(100)$ & 241 & $(100)$ & $1^{\text {b }}$ \\
14 days prior N (\%) & 5 & $(100)$ & 230 & $(96)$ & \\
Infections No & 0 & $(0)$ & 11 & $(4)$ & \\
Yes & 3 & $(100)$ & 252 & $(100)$ & $1^{\text {b }}$ \\
21 days prior N (\%) & 3 & $(100)$ & 241 & $(96)$ & \\
Infections No & 0 & $(0)$ & 11 & $(4)$ & \\
Yes & & & & & \\
\hline
\end{tabular}

(c)

\begin{tabular}{cccccc}
\hline & \multicolumn{5}{c}{ MTX + ADA } \\
\hline $\begin{array}{c}\text { Time when both medications were } \\
\text { discontinued }\end{array}$ & $\begin{array}{c}\text { Discontinued } \\
\text { medication }\end{array}$ & $\begin{array}{c}\text { Continued } \\
\text { medication }\end{array}$ & P \\
\hline 14 days prior N (\%) & 2 & $(100)$ & 111 & $(100)$ & $1^{\text {b }}$ \\
Infections No & 2 & $(100)$ & 106 & $(95)$ & \\
Yes & 0 & $(0)$ & 5 & $(5)$ & \\
28 days prior N (\%) & 1 & $(100)$ & 122 & $(100)$ & $1^{\text {b }}$ \\
Infections No & 1 & $(100)$ & 117 & $(96)$ & \\
Yes & 0 & $(0)$ & 5 & $(4)$ & \\
35 days prior N (\%) & 1 & $(100)$ & 124 & $(100)$ & $1^{\text {b }}$ \\
Infections No & 1 & $(100)$ & 119 & $(96)$ & \\
Yes & 0 & $(0)$ & 5 & $(4)$ & \\
\hline
\end{tabular}

Note: p-values are for those who discontinue both medications vs. those who continue both medications. Fisher's exact test (b) was used to exam the difference between the groups. 
combination regimens can be continued in the perioperative period without increasing the risk for infection-related complications.

Our study analyzed data from the United States VA encompassing 17 years and 106 surgical sites. We studied the two most commonly used combination therapies, and found that the infection rate and the length of post-operative hospital stays were similar in those continuing and discontinuing both MTX + HCQ and MTX + TNF during the perioperative period. In addition, the death rate is close to 0 in the MTX + TNF group. Although the rate of post-operative death in 90 days is the greatest (7\%) in MTX + HCQ discontinued medication subgroup, the small sample size ( 1 patient) is not adequate to make clinical implication. Similarly, although the post-operative infection rate and death looks higher in the MTX + TNF continuing medication group, the small number of patients in the discontinuing medication group makes it difficult to make comparisons or definitive conclusions.

There are several limitations to our study. First, the VA population is older than the general RA population, predominantly male, and non-Hispanic Caucasian. As such, the extrapolation of these results to the general population may not be entirely valid. Clinical indices of disease severity, such as Clinical Disease Activity Index (CDAI) or the Disease Activity Score in 28 Joints (DAS-28) were not included in the study due to incomplete documentation. Like most other studies on this topic, there is no measurement of post-operative RA flare available to us to determine whether the rate of RA flare is decreased with continuation of RA therapy. Finally, the use of a refill dates in the pharmacy database as a surrogate marker for continuation or cessation of medication have its limitations. Specifically, it does not allow us to distinguish the reasons for immunosuppressant discontinuation. Discontinuation could be due to low disease activity, surgeon preference, etc. If there were to be a significant improvement in the patient group who stopped their medicines prior to surgery, it would be difficult to give clear guidance as to when a given medicine should be stopped. The algorithm used to determine whether the medication was discontinued or not was validated at Houston VA. Nationwide validation was not done. However, given that we were able to reproduce the monotherapy study results with our current national database that was previously done with the Houston VA database [22], this limitation is less of a concern. Finally, the medication patients received outside of the VA system is not captured in our database. Due to high cost of most BAs, most patients refill the medications via VA pharmacy. Therefore, incomplete pharmacy data is less of a concern.

Our study provides evidence that continuing either MTX + TNF or MTX + HCQ combination during perioperative period does not increase post-operative infection rate compared with their discontinuation prior to surgery. The small number of cases of infection and death makes it difficult to draw relevant statistical interpretations for our study. However, it is reassuring to know that current surgical techniques have minimized post-operative infection complications even in individuals who are immunocompromised with DMARDs and BAs, like 
TNF- $\alpha$ inhibitors. It is better than using steroid post operatively, which is notorious for increasing rate of infection and delay wound healing. We recommend continuing MTX + HCQ and MTX + TNF during perioperative period if the main concern for discontinuation is post-operative infection, length of hospital stay or death.

\section{Acknowledgements}

The Surgical Quality Data Use Group (SQDUG) Coordinating Office, ITHS voucher award, UW Division of Rheumatology, NIH T32.

\section{Conflicts of Interest}

The authors declare no conflicts of interest regarding the publication of this paper.

\section{References}

[1] Lawrence, R.C., et al. (1998) Estimates of the Prevalence of Arthritis and Selected Musculoskeletal Disorders in the United States. Arthritis \& Rheumatology, 41, 778-799. https://doi.org/10.1002/1529-0131(199805)41:5<778::AID-ART4>3.0.CO;2-V

[2] Goodman, S.M., et al. (2014) Patients with Rheumatoid Arthritis Are More Likely to Have Pain and Poor Function after Total Hip Replacements than Patients with Osteoarthritis. The Journal of Rheumatology, 41, 1774-1780. https://doi.org/10.3899/jrheum.140011

[3] Bongartz, T., et al. (2008) Incidence and Risk Factors of Prosthetic Joint Infection after Total Hip or Knee Replacement in Patients with Rheumatoid Arthritis. Arthritis Care \& Research, 59, 1713-1720. https://doi.org/10.1002/art.24060

[4] Karukonda, S.R., et al. (2000) The Effects of Drugs on Wound Healing-Part II. Specific Classes of Drugs and Their Effect on Healing Wounds. International Jour nal of Dermatology, 39, 321-333. https://doi.org/10.1046/j.1365-4362.2000.00949.x

[5] Pieringer, H., Stuby, U. and Biesenbach, G. (2007) Patients with Rheumatoid Arthritis Undergoing Surgery: How Should We Deal with Antirheumatic Treatment? Seminars in Arthritis and Rheumatism, 36, 278-286. https://doi.org/10.1016/j.semarthrit.2006.10.003

[6] Akkara Veetil, B.M. and Bongartz, T. (2012) Perioperative Care for Patients with Rheumatic Diseases. Nature Reviews Rheumatology, 8, 32-41. https://doi.org/10.1038/nrrheum.2011.171

[7] Grennan, D.M., et al. (2001) Methotrexate and Early Postoperative Complications in Patients with Rheumatoid Arthritis Undergoing Elective Orthopaedic Surgery. Annals of the Rheumatic Diseases, 60, 214-217. https://doi.org/10.1136/ard.60.3.214

[8] Pieringer, H., Stuby, U. and Biesenbach, G. (2008) The Place of Methotrexate Perioperatively in Elective Orthopedic Surgeries in Patients with Rheumatoid Arthritis. Clinical Rheumatology, 27, 1217-1220. https://doi.org/10.1007/s10067-008-0888-y

[9] Luqmani, R., et al. (2009) British Society for Rheumatology and British Health Professionals in Rheumatology Guideline for the Management of Rheumatoid Arthritis (after the First 2 Years). Rheumatology (Oxford), 48, 436-439. https://doi.org/10.1093/rheumatology/ken450a

[10] Visser, K., et al. (2009) Multinational Evidence-Based Recommendations for the 
Use of Methotrexate in Rheumatic Disorders with a Focus on Rheumatoid Arthritis: Integrating Systematic Literature Research and Expert Opinion of a Broad International Panel of Rheumatologists in the 3E Initiative. Annals of the Rheumatic Diseases, 68, 1086-1093. https://doi.org/10.1136/ard.2008.094474

[11] Bombardier, C., et al. (2012) Canadian Rheumatology Association Recommendations for the Pharmacological Management of Rheumatoid Arthritis with Traditional and Biologic Disease-Modifying Antirheumatic Drugs: Part II Safety. The Journal of Rheumatology, 39, 1583-1602. https://doi.org/10.3899/jrheum.120165

[12] Den Broeder, A.A., et al. (2007) Risk Factors for Surgical Site Infections and Other Complications in Elective Surgery in Patients with Rheumatoid Arthritis with Special Attention for Anti-Tumor Necrosis Factor: A Large Retrospective Study. The Journal of Rheumatology, 34, 689-695.

[13] Bibbo, C. and Goldberg, J.W. (2004) Infectious and Healing Complications after Elective Orthopaedic Foot and Ankle Surgery during Tumor Necrosis Factor-Alpha Inhibition Therapy. Foot \& Ankle International, 25, 331-335. https://doi.org/10.1177/107110070402500510

[14] Giles, J.T., et al. (2006) Tumor Necrosis Factor Inhibitor Therapy and Risk of Serious Postoperative Orthopedic Infection in Rheumatoid Arthritis. Arthritis \& Rheumatology, 55, 333-337. https://doi.org/10.1002/art.21841

[15] Ruyssen-Witrand, A., et al. (2007) Complication Rates of 127 Surgical Procedures Performed in Rheumatic Patients Receiving Tumor Necrosis Factor Alpha Blockers. Clinical and Experimental Rheumatology, 25, 430-436.

[16] Dixon, W.G., et al. (2007) Reduction in the Incidence of Myocardial Infarction in Patients with Rheumatoid Arthritis Who Respond to Anti-Tumor Necrosis Factor Alpha Therapy: Results from the British Society for Rheumatology Biologics Register. Arthritis \& Rheumatology, 56, 2905-2912. https://doi.org/10.1002/art.22809

[17] Goodman, S.M., et al. (2017) 2017 American College of Rheumatology/American Association of Hip and Knee Surgeons Guideline for the Perioperative Management of Antirheumatic Medication in Patients With Rheumatic Diseases Undergoing Elective Total Hip or Total Knee Arthroplasty. Arthritis \& Rheumatology, 69, 1538-1551. https://doi.org/10.1002/art.40149

[18] Ding, T., et al. (2010) BSR and BHPR Rheumatoid Arthritis Guidelines on Safety of Anti-TNF Therapies. Rheumatology (Oxford), 49, 2217-2219. https://doi.org/10.1093/rheumatology/keq249a

[19] Liote, F. (2005) Armentarium and Strategies for the Treatment of Rheumatoid Arthritis. La Revue du Praticien, 55, 2146-2160.

[20] Ng, B., et al. (2012) Identification of Rheumatoid Arthritis Patients Using an Administrative Database: A Veterans Affairs Study. Arthritis Care \& Research (Hoboken), 64, 1490-1496. https://doi.org/10.1002/acr.21736

[21] Thomas, S.L., et al. (2008) How Accurate Are Diagnoses for Rheumatoid Arthritis and Juvenile Idiopathic Arthritis in the General Practice Research Database? Arthritis \& Rheumatology, 59, 1314-1321. https://doi.org/10.1002/art.24015

[22] Abou Zahr, Z., et al. (2014) Perioperative Use of Anti-Rheumatic Agents Does Not Increase Early Postoperative Infection Risks: A Veteran Affairs' Administrative Database Study. Rheumatology International, 35, 265-272.

[23] Charlson, M.E., et al. (1987) A New Method of Classifying Prognostic Comorbidity in Longitudinal Studies: Development and Validation. Journal of Chronic Diseases, 40, 373-383. https://doi.org/10.1016/0021-9681(87)90171-8

[24] Radner, H., Smolen, J.S. and Aletaha, D. (2011) Comorbidity Affects All Domains of 
Physical Function and Quality of Life in Patients with Rheumatoid Arthritis. Rheumatology (Oxford), 50, 381-388. https://doi.org/10.1093/rheumatology/keq334

[25] Deyo, R.A., Cherkin, D.C. and Ciol, M.A. (1992) Adapting a Clinical Comorbidity Index for Use with ICD-9-CM Administrative Databases. Journal of Clinical Epidemiology, 45, 613-619. https://doi.org/10.1016/0895-4356(92)90133-8

[26] Boyko, E.J., et al. (2000) US Department of Veterans Affairs Medical Care System as a Resource to Epidemiologists. American Journal of Epidemiology, 151, 307-314. https://doi.org/10.1093/oxfordjournals.aje.a010207

[27] Khuri, S.F., et al. (1998) The Department of Veterans Affairs' NSQIP: The First National, Validated, Outcome-Based, Risk-Adjusted, and Peer-Controlled Program for the Measurement and Enhancement of the Quality of Surgical Care. National VA Surgical Quality Improvement Program. Annals of Surgery, 228, 491-507. https://doi.org/10.1097/00000658-199810000-00006

[28] Narula, N., Charleton, D. and Marshall, J.K. (2013) Meta-Analysis: Peri-Operative Anti-TNFalpha Treatment and Post-Operative Complications in Patients with Inflammatory Bowel Disease. Alimentary Pharmacology \& Therapeutics, 37, 1057-1064. https://doi.org/10.1111/apt.12313

[29] Colombel, J.F., et al. (2004) Early Postoperative Complications Are Not Increased in Patients with Crohn's Disease Treated Perioperatively with Infliximab or Immunosuppressive Therapy. The American Journal of Gastroenterology, 99, 878-883. https://doi.org/10.1111/j.1572-0241.2004.04148.x 